\title{
Morfologia e vascularização do baço de jacaré (Caiman crocodilus yacare - Daudin, 1802)
}

\author{
Raphaella Barbosa Meirelles ${ }^{1}$ \\ Rosângela Felipe Rodrigues ${ }^{2}$ \\ Alan Peres Ferraz de Melo ${ }^{3 *}$ \\ ${ }^{1}$ Curso de Graduação em Medicina Veterinária \\ Universidade Federal de Goiás, Campus Avançado de Jataí - Unidade Jatobá \\ BR 364, km 192, 3800, Laboratório de Sanidade Animal, Setor Parque Industrial \\ Caixa Postal 03, CEP 75801-615, Jataí - GO, Brasil \\ ${ }^{2}$ Faculdade de Medicina Veterinária e Zootecnia, Universidade de São Paulo \\ Departamento de Anatomia dos Animais Domésticos e Silvestres \\ Avenida Prof. Dr. Orlando Marques de Paiva, 87, CEP 05508-270, São Paulo - SP, Brasil \\ ${ }^{3}$ Faculdade de Engenharia de Ilha Solteira - UNESP, Departamento de Biologia e Zootecnia \\ Rua Monção, 226, Zona Norte, CEP 15385-000, Ilha Solteira - SP, Brasil. \\ * Autor para correspondência \\ alanmelo@usp.br
}

Submetido em 20/08/2012

Aceito para publicação em 27/08/2013

\section{Resumo}

O Caiman crocodilus yacare é encontrado do norte da Argentina até o sul da bacia Amazônica, ocorrendo principalmente no Pantanal. Sua alimentação consiste de peixes e outros vertebrados aquáticos e invertebrados, como caranguejos, caramujos e insetos. Seu comprimento pode chegar a $3 \mathrm{~m}$ e essa espécie é importante porque proporciona controle biológico de outras espécies animais, ao se alimentar de indivíduos fracos, velhos e doentes, incapazes de escapar de seu ataque. Foram utilizados 15 jacarés, machos e fêmeas jovens, empregando técnicas histológicas; técnicas de injeção com Neoprene látex 450 e acetato de vinila; e técnicas radiográficas para observar particularidades do baço nessa espécie. O órgão apresenta forma cônica, sendo mais espesso na sua extremidade cranial e afilando-se em sua extremidade caudal. O baço envolveu a artéria mesentérica cranial, que se dirigiu aos intestinos, desde sua origem na artéria celíaca até o seu terço médio, pelo parênquima lienal em todas as preparações. A irrigação do baço de jacaré foi originada da artéria celíaca, por meio de seu ramo, a artéria mesentérica cranial, a qual se ramificou em artérias lienais, somente no interior desse órgão. As veias lienais apresentaram-se como as veias lienais cranial, craniomedial, medial e caudal que drenam da cápsula lienal à região medular, passando pela região cortical e dirigindo-se à veia porta hepática. $\mathrm{O}$ baço de jacaré não apresentou correspondência entre as artérias e as veias responsáveis pela vascularização de um determinado território lienal, mas foram observadas artérias que irrigaram e veias que drenaram áreas particulares do parênquima lienal.

Palavras-chave: Baço; Caiman crocodilus yacare; Jacaré

\section{Abstract}

Spleen morphology and vascularization in the alligator (Caiman crocodilus yacare - Daudin, 1802). The Caiman crocodilus yacare is found from northern Argentina to the southern Amazon basin, mainly 
occurring in Pantanal. Its food consists of fishes and other aquatic vertebrates and invertebrates, such as crabs, winkles, and insects. Its length can reach 3 meters and this species is important because it provides biological control of other animal species, by feeding on weak, old, and ill individuals, unable to escape its attack. A total of 15 alligators were used, young males and females, using histological techniques; injection techniques with Neoprene latex 450 and vinyl acetate; and radiographic techniques to observe particularities of spleen in this species. The organ has a conical shape, being thicker at its cranial end and tapering at its caudal end. Spleen involved the cranial mesenteric artery, which went towards the intestines, from its origin in the celiac artery until its middle third, through the splenic parenchyma in all preparations. Spleen irrigation in the alligator was originated from the celiac artery, through its branch, the cranial mesenteric artery, which branched into splenic arteries, only within this organ. The splenic veins showed up as the cranial, craniomedial, medial, and caudal splenic veins which drain from the splenic capsule to the medullary region, going through the cortical region and going towards the hepatic portal vein. Spleen in the alligator showed no correspondence between the arteries and veins responsible for the vascularization of a certain splenic territory, but one observed arteries irrigating and veins draining particular areas of the splenic parenchyma.

Key words: Alligator; Caiman crocodiles yacare; Spleen

\section{Introdução}

Devido à grande crise ambiental que passa nosso planeta, há a necessidade de se resgatar os diversos organismos presentes em habitats naturais que estão desaparecendo. Estes organismos, fauna e flora, necessitam serem conservados intactos para que possamos estudá-los detalhadamente. Tentando solucionar este problema, o Instituto Brasileiro de Meio Ambiente (IBAMA) permite que pessoas e empresas possam criar espécies silvestres em cativeiro. Este é o método que admite, inicialmente, conservar as espécies presentes no planeta, permitindo ainda, que elas possam ser estudadas minuciosamente com o intuito de melhor entender suas necessidades de sobrevivência.

Sabendo que animais silvestres quando criados em cativeiros apresentam comportamentos e necessidades distintas daqueles encontrados em seu habitat natural, pretendeu-se estudar inicialmente o baço de jacaré (Caiman crocodilus yacare), uma vez que este animal apresenta algumas características particulares.

$O$ baço de jacarés de gênero diferente e de outros répteis já foram estudados por autores como Zapata et al. (1981), Tanaka e Hirahara (1995), Tanaka e Elsey (1997) e Faria (2000; 2003), mas nenhum dos autores referiu-se à segmentação do órgão.

Tanaka e Elsey (1997), estudando jacaré (Alligator mississiooiensis), descreveram que o baço apresenta-se em forma de feijão coberto por uma espessa cápsula.
O lado côncavo está direcionado ao pâncreas. Muitas veias estão presentes na cápsula. A haste segmentar da grande artéria intestinal, a artéria lieno-intestinal, penetra no órgão pelo pólo superior e corre em direção ao eixo central deixando o órgão pelo pólo inferior. Muitos ramos periféricos originam-se da artéria axial em direção à cápsula

O trabalho objetivou estudar a forma do baço, sua sintopia e o comportamento das artérias e das veias lienais, tentando evidenciar ou não a segmentação anátomo-cirúrgica do órgão.

\section{Material e Métodos}

Utilizou-se 15 jacarés (Caiman crocodylus yacare), entre machos e fêmeas jovens, doados pelo criador Osvaldo Roberto Scabine proprietário da Fazenda Água Limpa, Município de Balsamo, Estado de São Paulo, registrado no Instituto Brasileiro do Meio Ambiente e dos Recursos Naturais Renováveis (IBAMA), sob $\mathrm{n}$ - 269.858. Os animais foram ortotanasiados na propriedade supra mencionada utilizando-se éter etílico PA, segundo a Resolução no 712 do Conselho Federal de Medicina Veterinária. Logo após o óbito procedeu-se à abertura da cavidade pleuroperitoneal com o objetivo de identificar a aorta esquerda. Em seguida, em dois animais, isolou-se a aorta direita e a aorta esquerda foi canulada com agulha de calibre compatível com o referido vaso, por onde foi infundido substância de 
Neoprene látex 450 corado com pigmento específico. Quanto às veias lienais estas foram igualmente injetadas com a mesma substância por meio da veia porta hepática. Após esta infusão arterial, foi possível a visualização de todas as artérias e veias que vascularizavam o baço, uma vez que os referidos vasos foram corados pela substância injetada.

As vísceras de doze outros animais foram colocadas em recipiente com água corrente para retirar o excesso de sangue. Em seguida, os vasos que se dirigiam ao baço foram identificados. Estes foram canulados com agulha compatível ao calibre dos vasos, injetando-se água ligeiramente aquecida para que o sangue, ainda presente nas artérias e nas veias, fosse eliminado. Posteriormente, infundiu-se acetona para só então preencher o vaso com acetato de vinila corado com pigmento específico, com cores diferentes para artéria e veia. Em seguida, os baços foram colocados em recipiente contendo ácido sulfúrico a $30 \%$ para ocorrer à corrosão do parênquima lienal por um período de $72 \mathrm{~h}$. Transcorrido esse período, os baços foram retirados da solução e lavados em água corrente para remoção dos resíduos de parênquima, obtendo-se moldes do referido órgão que foram analisados e fotodocumentados.

Um animal também foi submetido à mesma técnica de evidencialização de vaso, porém, foi acrescido ao látex corado, contraste radiopaco, na proporção de 1:1.

Em seguida, o órgão foi radiografado em aparelho da marca Raicenter, de $600 \mathrm{~mA}$ e $120 \mathrm{Kv}$, modelo RC 600 plus, mesa radiológica com grade e sistema "potterbucky" recipromático tipo "par speed", ampola de Raio X de ânodo giratório, no Setor de Diagnóstico por Imagens do Hospital Veterinário Dr. Halim Atique do Centro Universitário de Rio Preto - UNIRP. Para esta técnica utilizou-se o filme radiográfico marca Kodak, tamanho 24x30 de acordo com o tamanho do órgão, em chassi metálico portando telas intensificadoras cronexhi plus.

Sabendo-se que aves e répteis são animais que apresentam grande semelhança anatômica optou-se pela nomenclatura de Baumel et al. (1993), que estudaram a anatomia das aves.

FIGURA 1: Fotomacrografia da cavidade pleuroperitoneal de um jacaré (Caiman crocodylus yacare), vista ventral, onde se identifica: aorta esquerda (ae), aorta direita $(\downarrow)$, trato anastomótico $(*)$, aorta comum $(\mathrm{ac})$, artéria mesentérica cranial $(\mathrm{mc})$, artéria mesentérica caudal (md), jejuno (J), colo transverso (CT), vesícula biliar (VB), baço (B), ventrículo gástrico (V) e duodeno (D).

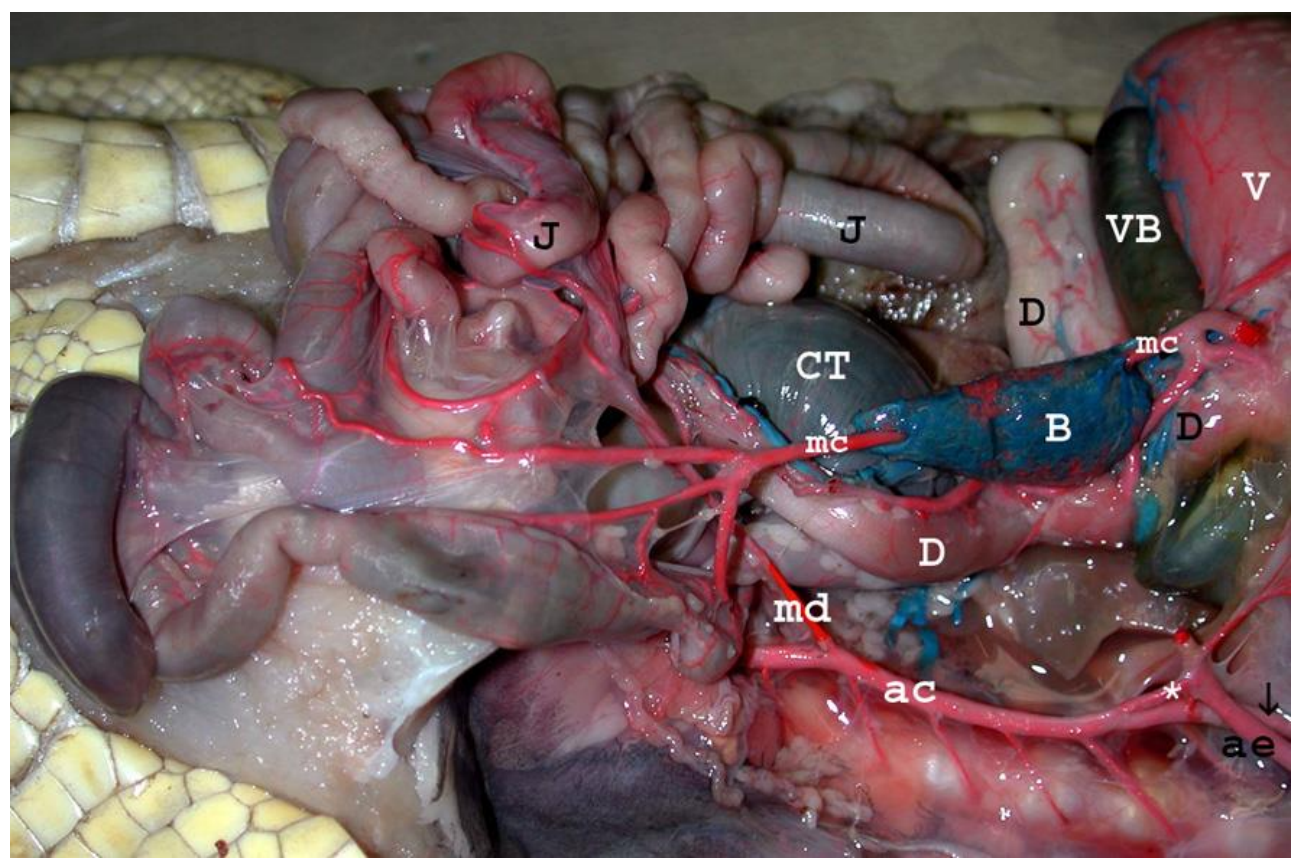




\section{Resultados}

\section{Topografia e irrigação do baço}

O baço apresentou em 100\% dos casos forma cônica, sendo mais espesso na sua extremidade cranial, afilando-se em sua extremidade caudal. Revelou localização mediana na cavidade pleuroperitoneal, estando em sintopia com o fígado em sua extremidade cranial, com o ventrículo gástrico e vesícula biliar à esquerda, duodeno e pâncreas à direita e cólon transverso em sua extremidade caudal (Figuras 1 a 4).

O baço envolveu a artéria mesentérica cranial, que se dirigiu aos intestinos, desde sua origem na artéria celíaca até o seu terço médio, pelo parênquima lienal em 100\% dos casos (Figuras 2, 4, 6 e 7). Durante seu percurso na longitude do baço, esta artéria era envolta pelo parênquima lienal superficialmente, nas extremidades do órgão e profundamente, na região central. Este comportamento esteve presente em 100\% dos casos (Figuras 5a e 5b).
Somente no interior do parênquima lienal é que a artéria mesentérica emitiu as artérias lienais que vão irrigar o baço em toda sua extensão, em todos os casos (Figura 6).

Identificou-se que as veias lienais drenavam toda á superfície do órgão e apresentavam-se com grande enovelamento. Estas veias foram nomeadas de cranial à caudal em veias lienais cranial, mediocranial, médio e caudal, e apresentavam-se indo em direção à veia porta hepática em 100\% dos casos (Figuras 2, 3 e 4).

\section{Segmentação do baço}

O baço de jacaré não apresentou uma segmentação anátomo-cirúrgica, no qual os ramos arteriais e as raízes venosas apresentariam uma correspondência. Houve, portanto, áreas distintas do órgão que são irrigadas por artérias lienais independentes, dividindo o baço em territórios distintos de irrigação. O mesmo ocorreu com as veias lienais. Estas puderam ser identificadas em três

FIGURA 2: Fotomacrografia da cavidade pleuroperitoneal de um jacaré (Caiman crocodylus yacare), vista ventral, onde se identifica: jejuno (J), duodeno (D), colo transverso (CT), ventrículo gástrico (V), pâncreas (P), artéria celíaca (ace), artéria mesentérica cranial (mc), artéria mesentérica caudal (md), veias lienais nomeadas de cranial, mediacranial, média e caudal (1, 2, 3 e 4 respectivamente) que realizam a drenagemm do baço $(\mathrm{B})$ em direção à veia porta hepática $(\mathrm{VP})$, baço $(\mathrm{B})$, esôfago $(\mathrm{E})$ e aorta esquerda (ae).

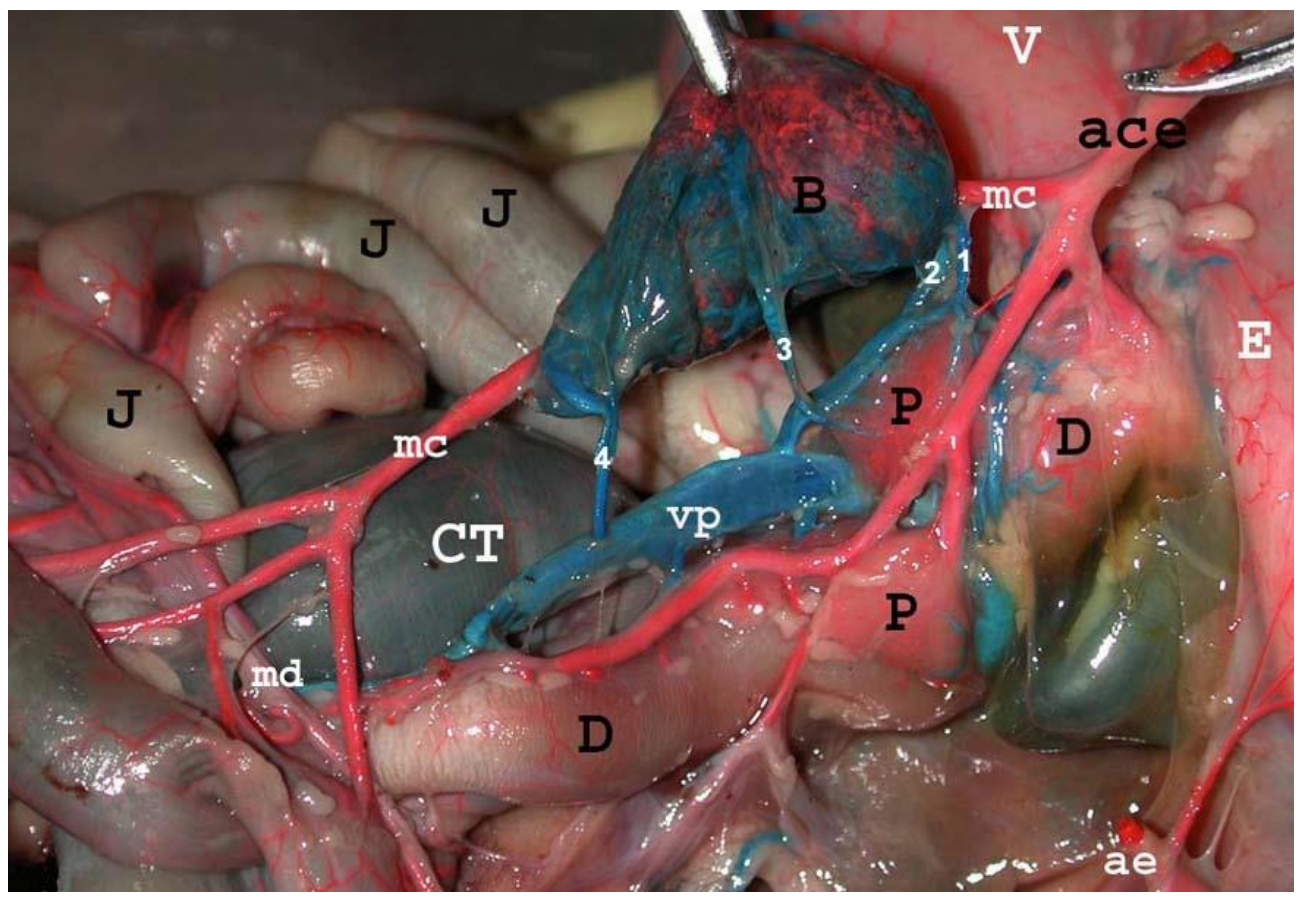


FIGURA 3: Fotomacrografia do molde do baço de jacaré (Caiman crocodylus yacare), acetato de vinila, onde se identifica: artéria celíaca (ace), artéria mesentérica cranial (mc), as veias lienais cranial, média e caudal (1, 2 e 3 respectivamente) drenando seus conteúdos em direção à veia porta hepática $(\mathrm{vp})$

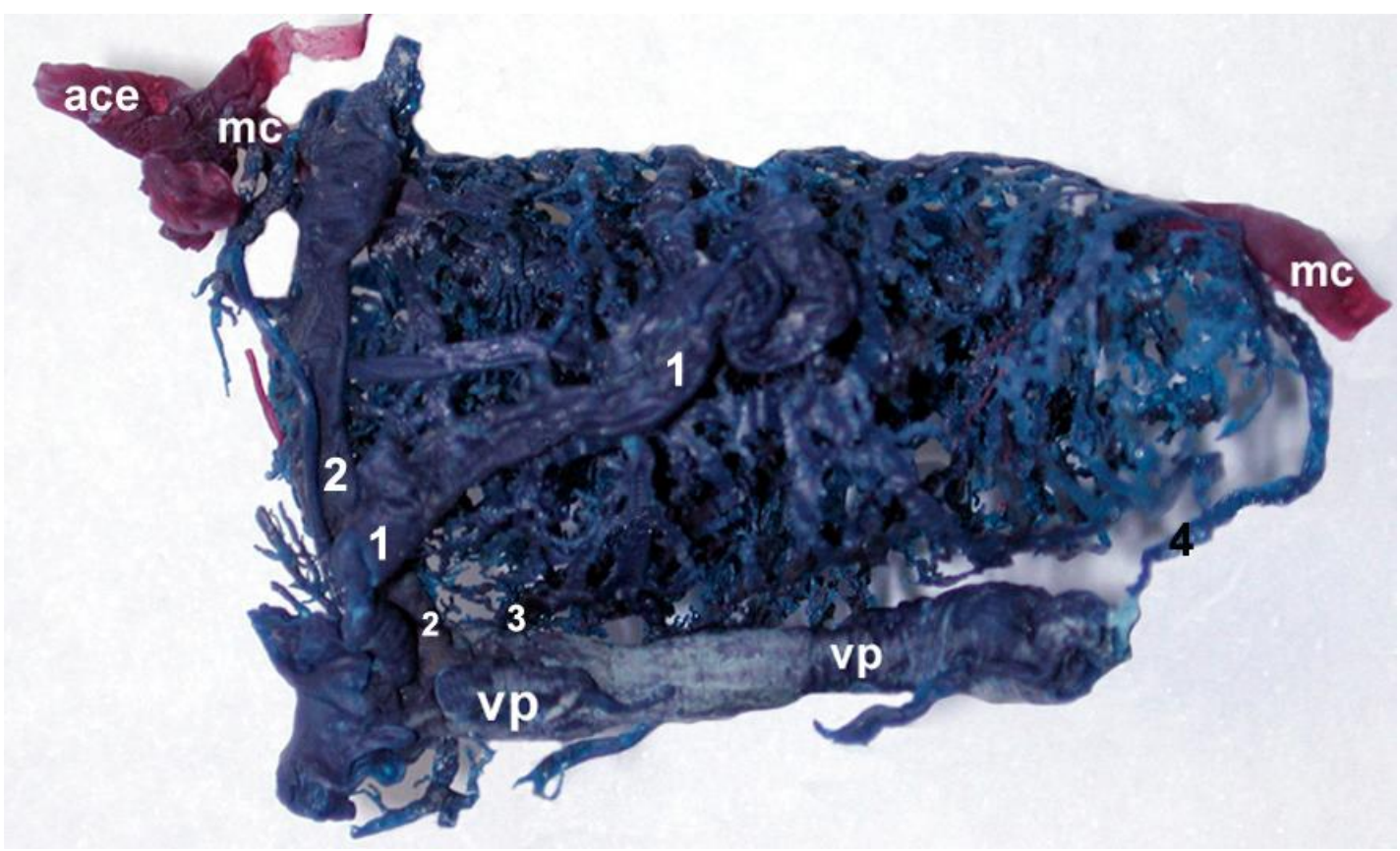

FIGURA 4: Fotomacrorafia do molde do baço de jacaré (Caiman crocodylus yacare), acetato de vinila, onde se identifica: artéria celíaca (ace), artéria mesentérica cranial interna ao baço (४), artérias lienais (个) no interior do órgão e as veias lienais cranial e média (1 e 2 respectivamente) encontrando-se antes de chegar na veia porta hepática (vp) e a veia lienal caudal (3) desembocando-se diretamente na veia porta hepática (vp) e o veia lineal cranial $(*)$.

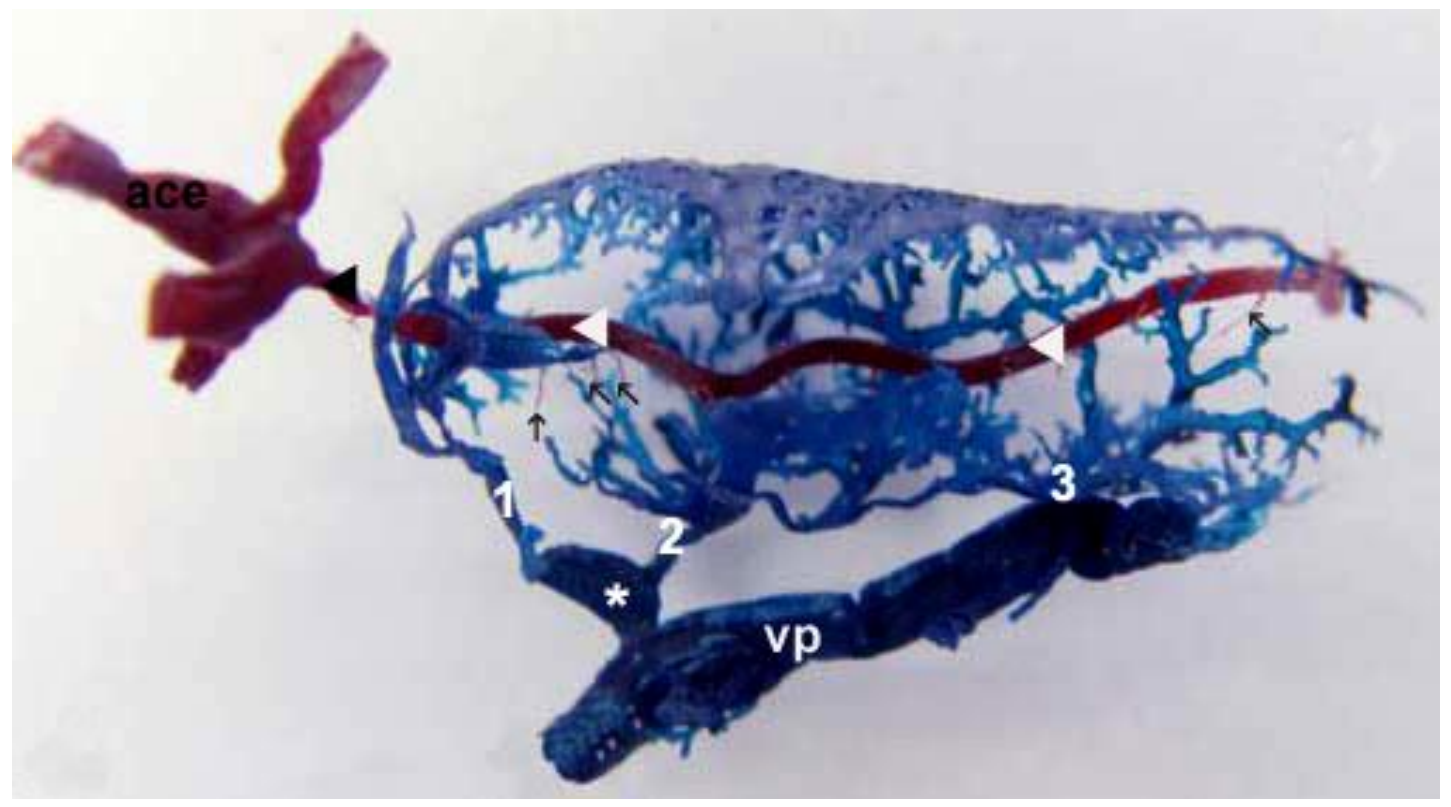


FIGURA 5: Fotomicrografica do baço de jacaré (Caiman crocodylus yacare). Em a nota-se a cápsula (ca), artéria mesentérica cranial (mc1) ocupando posição periférica no baço, corte transversal, e as seguintes estruturas: polpa branca (pb) e polpa vermelha (pv). Em b nota-se a cápsula (ca), artéria mesentérica cranial ( $\mathrm{mc} 2$ ) ocupando posição central no baço, corte transversal, e a polpa branca $(\mathrm{pb})$ e polpa vermelha $(\mathrm{pv})$. a-b paraplast, HE, $5 \mathrm{x}$.

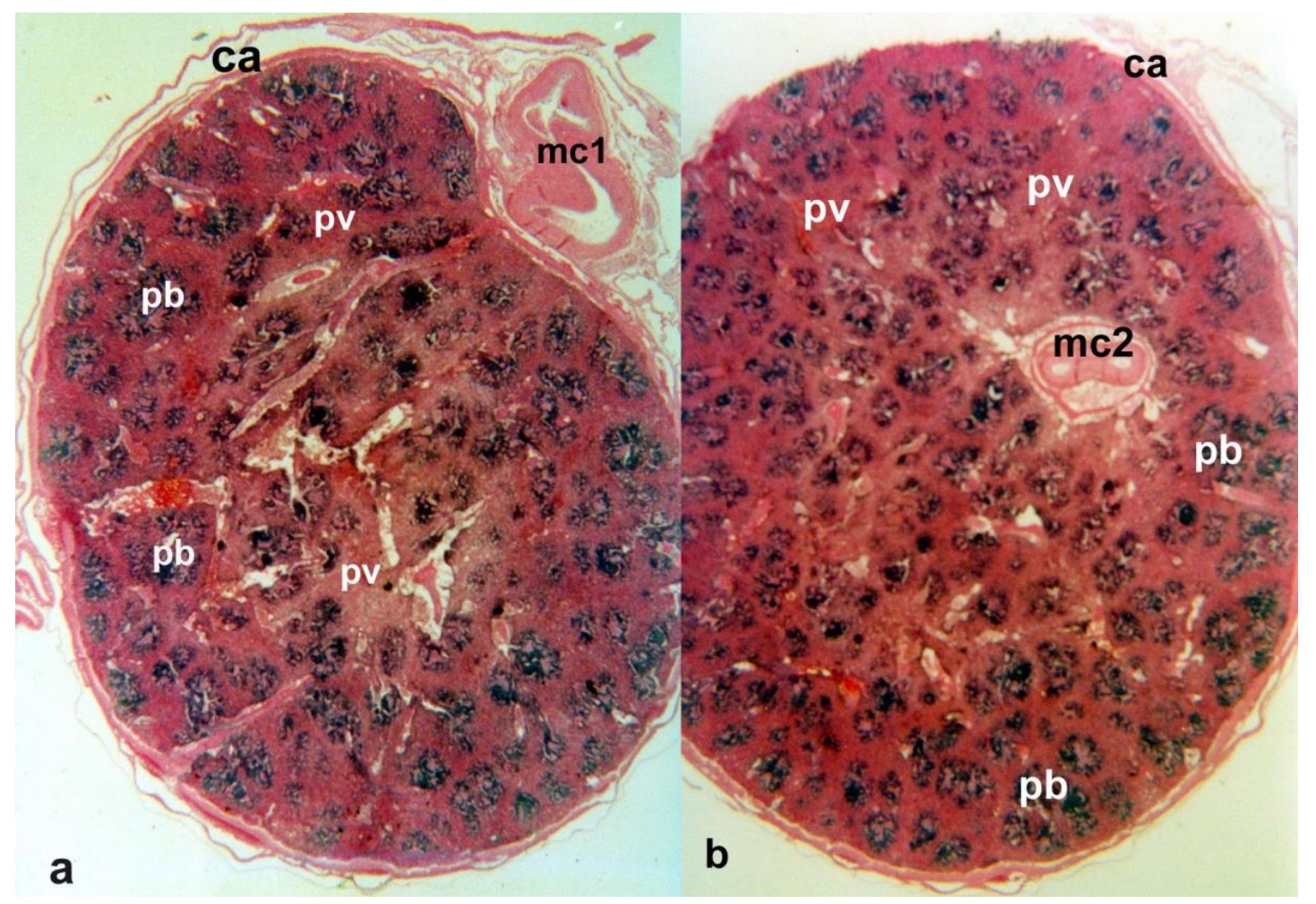

FIGURA 6: Fotomicrografia do baço de jacaré (Caiman crocodylus yacare), onde se identifica a artéria mesentérica cranial (mc) originando as artérias lienais (al), polpa branca (pb) e polpa vermelha (pv), corte longitudinal. paraplast, HE, 5x.

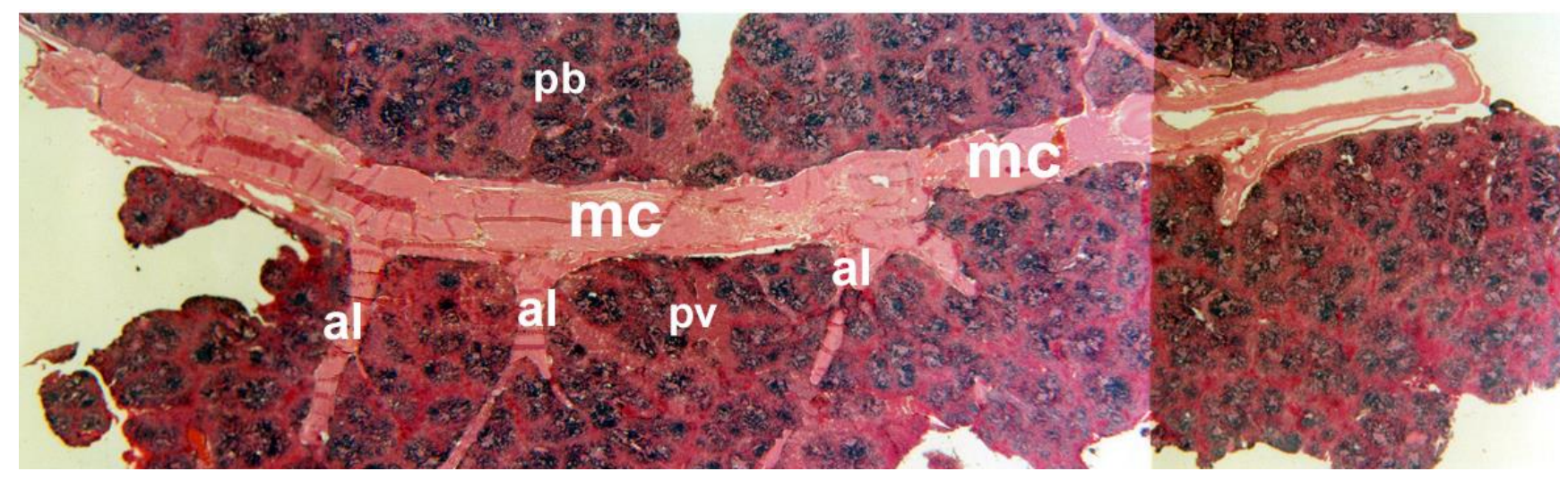


FIGURA 7: Radiografia da cavidade pleuroperitoneal de jacaré (Caiman crocodylus yacare), onde se identifica ventrículo gástrico (V), fígado $(\mathrm{F})$ e artéria mesentérica cranial (*) percorrendo o interior do baço (B).

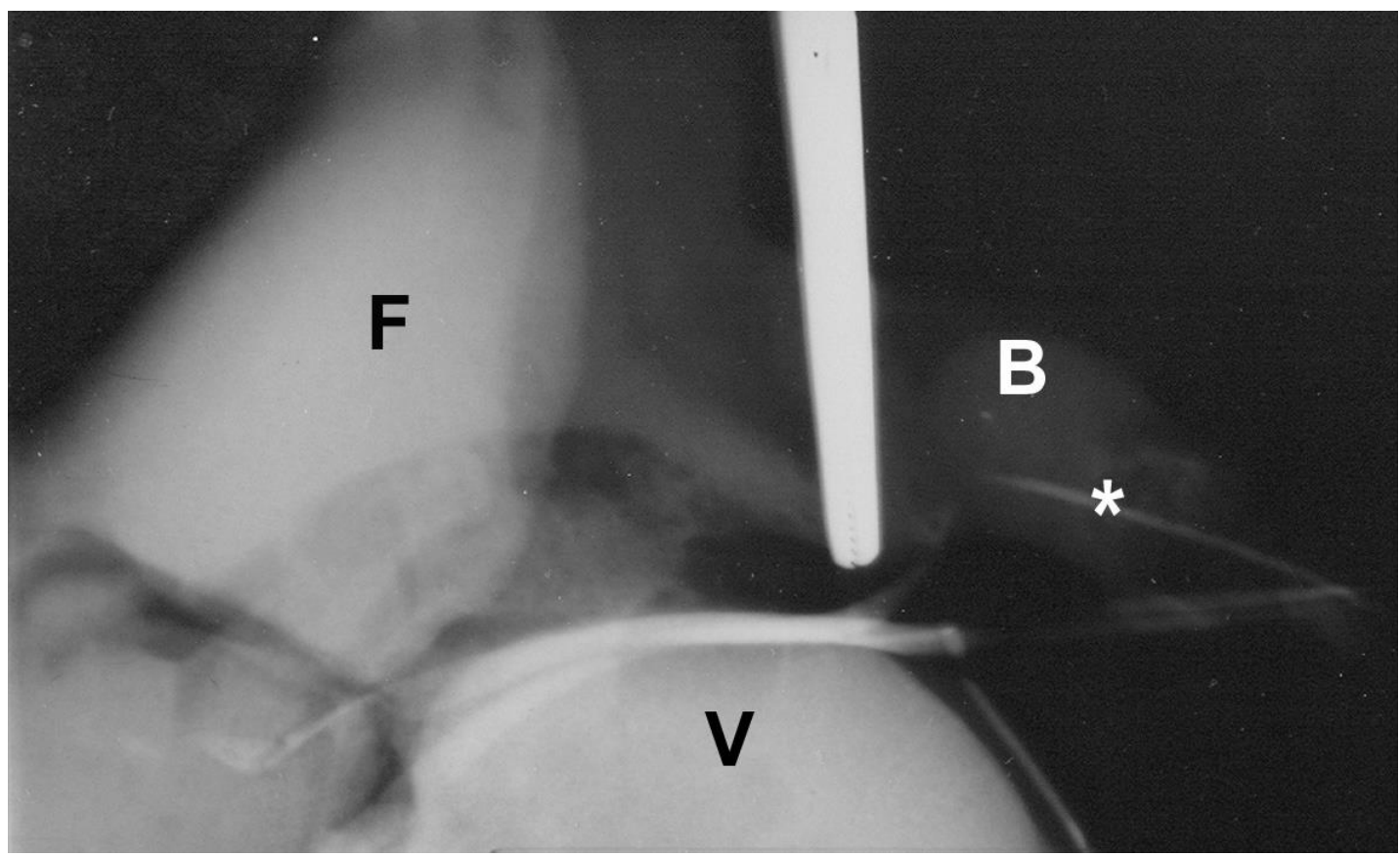

$(60 \%)$ ou quatro $(40 \%)$ destes territórios distintos de drenagem. Todas as veias lienais drenaram para a veia porta hepática (Figuras 2, 3 e 6).

\section{Discussão}

\section{Topografia e irrigação do baço}

Evidenciou-se o baço em posição mediana tendendo-se à esquerda, sendo esta observação comprovada por Baer (1965) e Grassé (1970), em répteis; Zapata et al. (1981) e Orr (1986), em tartarugas. Baer (1965) afirma, ainda, que sua posição pode mudar variando de acordo com o gênero, espécie, raça ou até mesmo de um indivíduo a outro dentro de uma mesma espécie. O baço dos animais estudados neste trabalho e dos estudados por Tanaka e Elsey (1997), em jacaré americano (Alligator mississiooiensis), são pertencentes a uma mesma espécie e apresentam a topografia da mesma maneira, não evidenciando o que foi afirmado por Baer (1965). Por sua vez, Faria (2003), em tartaruga, relata que o baço posiciona-se próximo ao cólon transverso, o que não foi evidenciado nos animais deste estudo.

Quanto à forma, os baços estudados apresentaram formato cônico, corroborando com o que foi descrito por Dittmann (1969, apud Tanaka e Elsey, 1997) e Tanaka e Elsey (1997). Romer e Parsons (1985) comentam que sua forma é variável e parece modificar rapidamente o seu contorno de acordo com os órgãos adjacentes. Outra particularidade referente a forma é ser mais espessa na sua extremidade cranial afilandose em sua extremidade caudal. Esta particularidade não foi relatada por nenhum dos autores consultados. Tanaka e Elsey (1997) evidenciaram que em animais jovens, ambos os pólos aparecem iguais em tamanho. No material alvo deste estudado, os animais eram jovens e o comportamento de afilar-se de cranial à caudal foi evidenciado em todos. Zapata et al. (1981) e Faria (2003), em tartarugas, e Dyce et al. (2010), em aves, não evidenciaram o baço de forma alongada, mas sim de forma oval ou espiralada. Acredita-se que este aspecto deva-se à diferença de espécie com o animal estudado no presente trabalho. 
O baço de jacaré apresentou sintopia com o fígado em sua extremidade cranial, com o ventrículo gástrico e vesícula biliar à esquerda, duodeno e pâncreas à direita e cólon transverso em sua extremidade caudal. Estes achados foram confirmados também por Baer (1965), Zapata et al. (1981), Tanaka e Elsey (1997) e Dyce et al. (2010).

Referente à irrigação do órgão, o baço envolveu a artéria mesentérica cranial, que se dirigiu aos intestinos, desde sua origem na artéria celíaca até o seu terço médio, pelo parênquima lienal. Esta observação também foi relatada por Tanaka e Elsey (1997) que a denominaram de artéria lieno-intestinal. Preferiu-se denominá-la como artéria mesentérica cranial como sugere Baumel et al. (1993). Dittmann (1969, apud Tanaka e Elsey, 1997) relata que a extremidade caudal do baço termina perto da raiz mesentérica, local onde emerge a artéria mesentérica cranial que irriga grande parte dos intestinos. Durante este percurso o baço abrigou parte da artéria mesentérica cranial transversalmente, sendo um envolvimento mais superficial nas extremidades e central medialmente; fato também relatado por Tanaka e Elsey (1997).

As artérias lienais possuíam origem a partir da artéria mesentérica cranial somente no interior do baço como também relatou Tanaka e Elsey (1997); e não penetraram no órgão pelo hilo como afirmam Zapata et al. (1981) e Tanaka e Hirahara (1995). Houve várias artérias lienais partindo da artéria mesentérica cranial e não uma como afirmam Romer e Parsons (1985) e Tanaka e Hirahara (1995).

As veias estavam presentes na superfície do órgão em grande enovelamento como também evidenciou Dittmann (1969, apud Tanaka e Elsey, 1997).

\section{Segmentação do baço}

Nenhum dos autores consultados relata sobre a segmentação do baço de jacaré ou mesmo de répteis ou aves. Evidenciou-se que o baço de jacaré (Caiman crocodylus yacare) não apresentou uma segmentação anátomo-cirúrgica clássica onde os ramos arteriais e as raízes venosas revelam uma correspondência, como afirma Di Dio (2002). O estudo da vascularização lienal interna evidenciou para o Caiman crocodylus yacare, ausência de correspondência entre as artérias e veias responsáveis pela vascularização de determinado território do parênquima lienal, embora ocorram artérias e veias que irrigam e drenam respectivamente, áreas particulares deste órgão.

Autores como Reginato e Melo (2004) nomeiam de segmento arterial a artéria que se dirige especificamente a um determinado território, e de segmento venoso o mesmo comportamento, só que presente nas veias. Seguindo esta definição pode-se dizer que o baço de jacaré (Caiman crocodylus yacare) apresentou vários segmentos arteriais, que estão intraparênquimais e três ou quatro segmentos venosos.

Podemos concluir que em relação à sintopia e forma, o baço de jacaré (Caiman crocodylus yacare) mostrou-se semelhante aos achados descritos para répteis de espécies diferentes, apresentando-se cônico, mais espesso em sua extremidade cranial e afilado na caudal.

Não apresentou variações individuais de localização, mostrando-se constante: mediana na cavidade pleuroperitoneal, relacionando-se com o fígado, ventrículo gástrico e vesícula biliar, duodeno, pâncreas e cólon transverso.

Não foi possível avaliar parâmetro idade, apontado na literatura como fator de variação da forma e sintopia, pois a amostra contemplou apenas animais jovens.

A irrigação do baço de jacaré (Caiman crocodylus yacare) derivou da artéria celíaca, por meio de seu ramo, artéria mesentérica cranial, a qual se ramificou em artérias lienais, somente no interior desse órgão. As veias lienais podem apresentar-se como veias lienais cranial, mediacranial, média e caudal que drenam da cápsula lienal á região medular, passando pela região cortical e se dirigindo a veia porta hepática.

O baço de jacaré (Caiman crocodylus yacare) não apresentou correspondência entre as artérias e as veias responsáveis pela vascularização de um determinado território lienal, mas foram evidenciadas artérias que irrigam e veias que drenam áreas particulares do parênquima lienal. 


\section{Agradecimentos}

Agradecimentos à Fundação de Amparo à Pesquisa do Estado de São Paulo FAPESP/Processo 02/09159-8.

\section{Referências}

BAER, J. G. Anatomie comparée des vertebrés. Suisse: Masson Griffer, 1965. 149 p.

BAUMEL, J. J.; KING, A. S.; BREAZILE, J. E.; EVANS, H. E.; VANDEN BERGER, J. C. Handbook of avian anatomy: Nomina Anatomica Avium. 2. ed. Cambridge: Nuttall Ornithological Club (Prepared by the International Committee on Avian Anatomical Nomenclature, World Association of Veterinary Anatomists), 1993. $779 \mathrm{p}$.

DI DIO, L. J. A. Tratado de anatomia aplicada. Vol. 1. 1. ed. São Paulo: Póllus Editorial, 2002. 248 p.

DYCE, K. M.; SACK, W. O.; WENSING, C. J. G. Tratado de anatomia veterinária. 4. ed. Rio de Janeiro: Guanabara Koogan, 2010. $878 p$

FARIA, M. D. A topografia e a irrigação do baço em tartarugas (Trachemys scripta elegans - WIED, 1839). 2003. 83 f. Dissertação (Mestrado em Anatomia dos Animais Domésticos) - Universidade de São Paulo, São Paulo. 2003.
FARIA, T. N. Descrição da origem, trajeto e número das principais artérias do jabuti “Geochelone carbonaria". 2000. 42 f. Dissertação (Mestrado em Anatomia dos Animais Domésticos) Universidade de São Paulo, São Paulo. 2000.

GRASSÉ, P. P. Traité de zoologie. Vol. 4. 6. ed. Paris: Masson, 1970. 715 p.

ORR, R. T. Biologia dos vertebrados. 5. ed. Roca: São Paulo, 1986. 508 p.

REGINATO, A. L.; MELO, A. P. F. Segmentação anátomo-cirúrgica em baços de queixada (Tayassu pecari - Link, 1975). Brazilian Journal of Veterinary Research and Animal Science, São Paulo, v. 41, n. 4, p. 281-285, 2004.

ROMER, A. S.; PARSONS, T. S. Anatomia comparada dos vertebrados. 7 ed. São Paulo: Atheneu, 1985. 390 p.

TANAKA, Y.; ELSEY, R. M. L. Light microscopic study of the alligator (Alligator mississippiensis) spleen with special reference to vascular architecture. Journal of Morphology, Malden, v. 233, n. 1, p. 43-52, 1997.

TANAKA, Y.; HIRAHARA, Y. Spleen of the snake (Elaphe climacophora) and intrasplenic vascular architecture. Journal of Morphology, Malden, v. 226, n. 2, p. 223-235, 1995.

ZAPATA, A.; LECETA, J.; BARRUTIA, M. G. Ultrastructure of splenic with pulp of the turtle, Mauremys caspica. Cell and Tissue Research, Berlin, n. 220, p. 845-855, 1981. 